\title{
Wound management using homemade vacuum dressing, affordable and customized (homemade vac)
}

\begin{abstract}
Introduction: The vacuum-assisted closure (VAC) has proved to be very promising in the management of difficult to heal wounds. However, the first reports about the use of negative pressure wound device came from Argenta and Morykwas in the year 1997. Though there are various commercially prepared and manufactured vacuum assisted closure dressing materials, these are often unavailable or unaffordable to patients in third world countries. Our "homemade" vacuum dressing has been found to be, affordable for our patients and most importantly effective in wound management.
\end{abstract}

Materials and methods: The homemade Vacuum Assisted closure dressing was used for the management of some wounds which presented at our centre. These wounds were irrigated and thoroughly debrided. Our homemade vacuum assisted closure dressings were subsequently applied.

Results: The wounds healed well with good granulation tissue. Subsequent split thickness skin graft (SSG) done had very good take. The VAC dressing often resulted in good wound contraction with no need for SSG.

Conclusion: In our practice our "home made" vacuum which was affordable and customized proved to be effective in wound management.

Keywords: wound, wound healing, wound dressing, vacuum assisted closure, mangled limb
Volume 6 Issue 2 - 202 I

\author{
Kwesi Okumanin Nsaful, Stephane Gentil \\ Plastic, Reconstructive Surgery and Burns Unit 37 Military \\ Hospital,Accra, Ghana
}

\begin{abstract}
Correspondence: Kwesi Okumanin Nsaful, Plastic, Reconstructive Surgery and Burns Unit 37 Military Hospital,
\end{abstract} Accra, Ghana, Email knsaful@yahoo.co.uk

Received: March 12, 202I | Published: April 01, 202 I

\section{Introduction}

A wound is defined as damage or disruption to the normal anatomical structure and function. ${ }^{1}$ Wounds may be anything ranging from a disruption in the epithelium to damage to structures such as tendons, muscles, vessels, nerves, parenchymal organs and even bone.$^{2}$ The Plastic Surgeon is consulted for the management of a wound with the hope of achieving a high rate of success in the wound healing. Thus the Plastic and Reconstructive surgeon has always sort to augment his armamentarium always looked for a new and more effective wound care techniques.

One such addition is the negative pressure wound therapy (NPWT) using the vacuum-assisted closure (VAC). This has proven very promising and is also beneficial in the management of difficult to heal wounds. The practice of exposing a wound to sub-atmospheric pressure is relatively new and was first described by Fleischmann et al. in the year $1993 .{ }^{3}$ However, the first reports about the use of negative pressure wound device came from Argenta and Morykwas in the year $1997 .{ }^{4}$

The use of controlled levels of negative pressure application has been shown to accelerate debridement and promote healing in various types of wounds. ${ }^{5}$ This optimum level of negative pressure appears to be around $125 \mathrm{mmHg}$ below ambient and there is evidence that this is most effective if applied in a cyclical fashion of five minutes on and two minutes off. ${ }^{5}$ Earlier studies used more conventional methods such as a wall suction apparatus or surgical vacuum bottles for creating the negative pressure. ${ }^{5}$ However, there were multiple problems present in the use of these conventional methods. ${ }^{6}$ In the year 1995, a commercial system for promoting vacuum-assisted closure (VAC) also known as vacuum therapy, vacuum sealing or topical negative pressure therapy was introduced into the United States market. ${ }^{5}$ This equipment, called the VAC, was designed to overcome some of the problems associated with conventional methods for the creation of negative pressure. The heart of the system is a microprocessor-controlled vacuum unit that is capable of providing controlled levels of continuous or intermittent sub-atmospheric pressure ranging from 25 to $200 \mathrm{mmHg}{ }^{5}$

It is postulated that various mechanisms might be responsible for the beneficial results obtained from VAC. ${ }^{6}$ It is proposed that the removal of the interstitial fluid decreases localized edema and increases blood flow, which in turn decreases tissue bacterial levels. It has since been advocated that the application of sub-atmospheric pressure produces mechanical deformation or stress within the tissue resulting in protein and matrix molecule synthesis and enhanced angiogenesis. ${ }^{7,8}$ The VAC treatment applies localized negative pressure applied to a special dressing positioned within the wound cavity or over a flap or graft that assists with the removal of interstitial fluid thereby decreasing localized edema and increasing the blood flow. ${ }^{5}$ Thus, decreasing the tissue bacterial levels. Also, the mechanical deformation of cells increases the rate of cell proliferation due to protein and matrix molecule synthesis. ${ }^{5}$

Argenta and Morykwas in the year 1997 reported the results of their study on 300 human subjects of which 296 patients responded favorably to the VAC. ${ }^{4}$ Similarly, numerous other papers have described the use of VAC in the treatment of a variety of wound types including soft tissue injuries prior to surgical closure, ${ }^{9}$ extensive degloving injuries, ${ }^{10,11}$ various grafting or reconstructive surgery. ${ }^{12}$ VAC has also been used in conjunction with split-thickness skin grafts in the treatment of burns, ${ }^{13-15}$ recalcitrant below-knee amputation wound pressure sores. ${ }^{16-21}$

The aim of this paper is to describe the use of our homemade Vacuum Assisted Closure and to highlight its effectiveness. We 
renamed ours, calling it Homemade Vacuum dressing, Affordable and Customized (i.e. Homemade VAC).

\section{Homemade vacuum dressing, affordable and customized}

For the wound dressing, patients are made to acquire

1. Foam from the market (i.e. foam sold on the market as foam mattress). This is sent to the CSSD to be

\section{Cling film wrap}

The wound is irrigated and washed with saline and dressing is done under aseptic conditions. The wound is covered with Vaseline gauze and this is padded with damp saline gauze. The sterile gauze is then applied over the wound and then the foam - which is often carved to meet the contour of the part body- is applied over the wound. The cling film wrap is then tightly applied to create an airtight environment around the wound. Plaster is applied at the edges of the cling film wrap to help seal off the wound.

By the use of a size Nelaton Catheter ( size used depends on the size of the wound ), the wound is connected to a suction machine to create the vacuum effect. The regimen employed was to have the suction machine on 2 hours and off for 1 hour. Effort was made to keep the suction pressures at between $50 \mathrm{mmHg}$ to $150 \mathrm{mmHg}$. It was noticed that children found the dressing uncomfortable and painful with high pressures.

The change of dressing was done every five days. However, occasionally the dressings were changed before day 5 when the dressing was noticed to be wet. For extensive wounds, the change of dressings was done under general anaesthesia or sedation.

\section{Case reports}

\section{Case I}

This the patient was a 37-year-old male who presented to the Trauma unit with a mangled left upper limb after he was involved in a road traffic accident as a passenger (Figure 1).

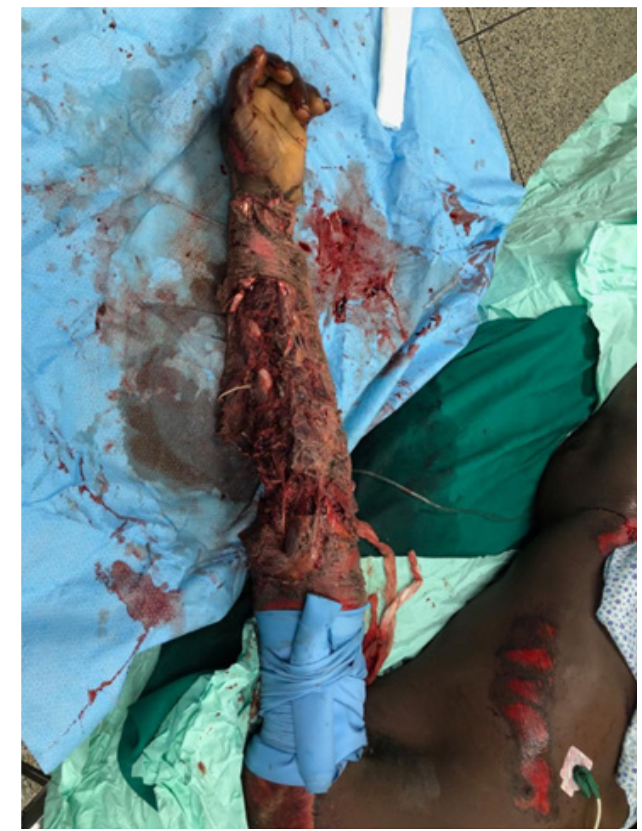

Figure I The mangled left upper limb of the patient on the day of presentation.
In this patient, the decision on whether to proceed with amputation or to salvage the mangled extremity was made based on the use of the Mangled Extremity Severity Score (MESS) developed by Johansen and colleagues. ${ }^{22}$ This has served as a useful tool that accurately predicted the need for amputation. The main evaluated variables are soft tissue injury, limb ischemia, presence and duration of shock, and the age of the patient. The scoring is done as follows;

\section{Skeletal/soft tissue injury}

i. Low Energy (stab wound, simple fracture, low energy gunshot wound)

ii. Medium Energy (open or multiple fractures, dislocation)

iii. High Energy (high speed motor vehicle collision or rifle gunshot wound)

iv. Very High Energy (above plus gross contamination)

\section{Limb Ischemia*}

i. Pulse reduced or absent but perfusion normal

ii. Pulseless; paresthesia, diminished capillary refill

iii. Cool, paralyzed, insensate, numb

\section{Shock}

Systolic blood pressure always $>90 \mathrm{mmHg} 0^{0}$

Systolic blood pressure transiently $<90 \mathrm{mmHg} 0^{1}$

Systolic blood pressure persistently $<90 \mathrm{mmHg} 0^{2}$

\section{Age (years)}

$<30$

$0^{0}$

$30-50$

$0^{1}$

$>50$

$0^{2}$

*Score doubled for ischemia time $>6$ hours

In this patient the MESS Score was estimated to be 7, because;

1. The injury was a very High Energy injury (above plus gross contamination) -4

2. There was diminished capillary refill -1

3. Systolic blood pressure always $>90 \mathrm{mmHg}-0$

4. He was 37 years old -2

A MESS score of 8 was chosen based on a prior study Johansen and colleagues, who suggested in their 2016 publication that a threshold of 8 was for limb salvage. ${ }^{23}$

He was taken to the theatre where under General anaesthesia thorough wound irrigation and debridement was done. On postoperative day 2, he was sent to theatre for second look wound inspection and debridement (Figure 2).

On day five our home made Vacuum dressing was applied. This was applied in theatre under General anaesthesia. The pressures were kept at between $100 \mathrm{mmHg}$ and $140 \mathrm{mmHg}$ (Figure 3).

After 7 days the vacuum dressing was changed again in theatre (Figure 4).

After 2 weeks of the vacuum dressing Split-thickness Graft was applied over the wound and Vacuum dressing was continued. 


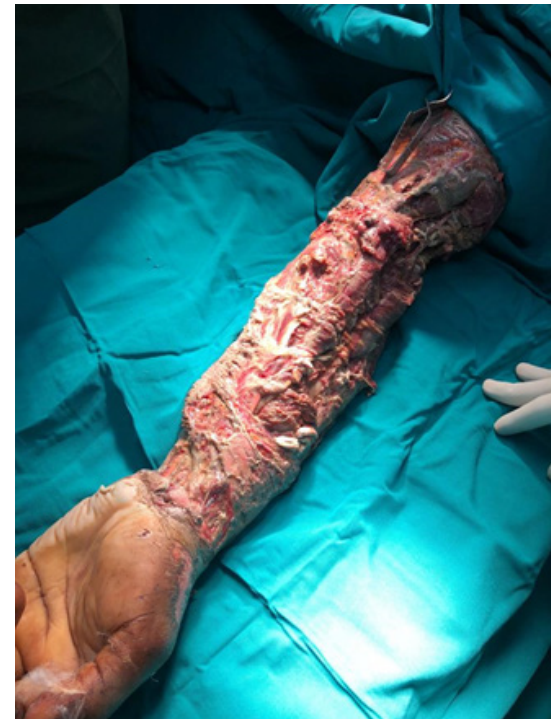

Figure 2 Upper limb during second look debridement.

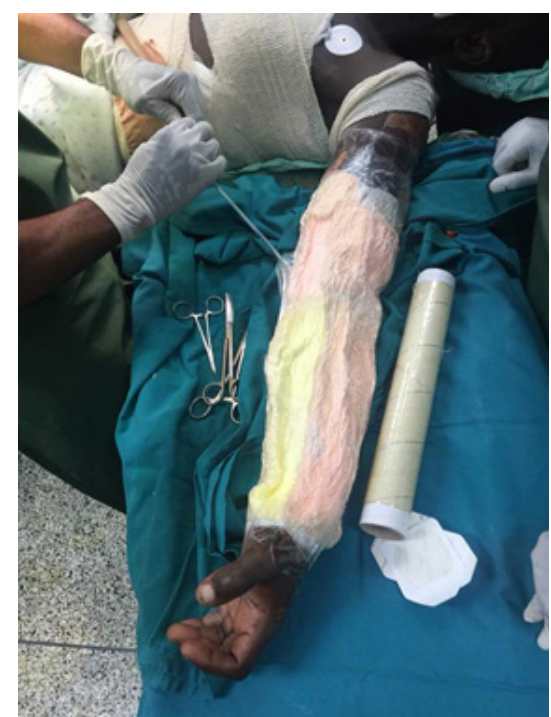

Figure 3 Homemade VAC dressing connected to the suction machine.

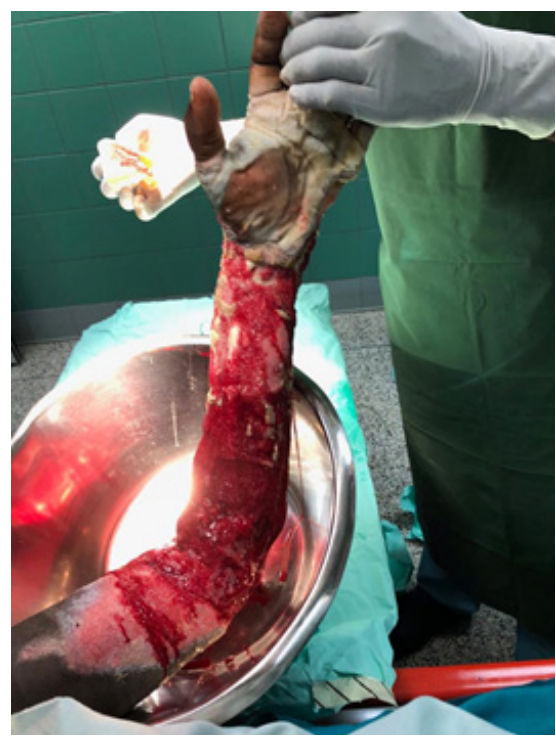

Figure 4 The Upper limb after 7 days of Home-made VAC.
The Graft take was about $45 \%$ and the use of the Vacuum dressing assisted in the wound healing (Figure 5).

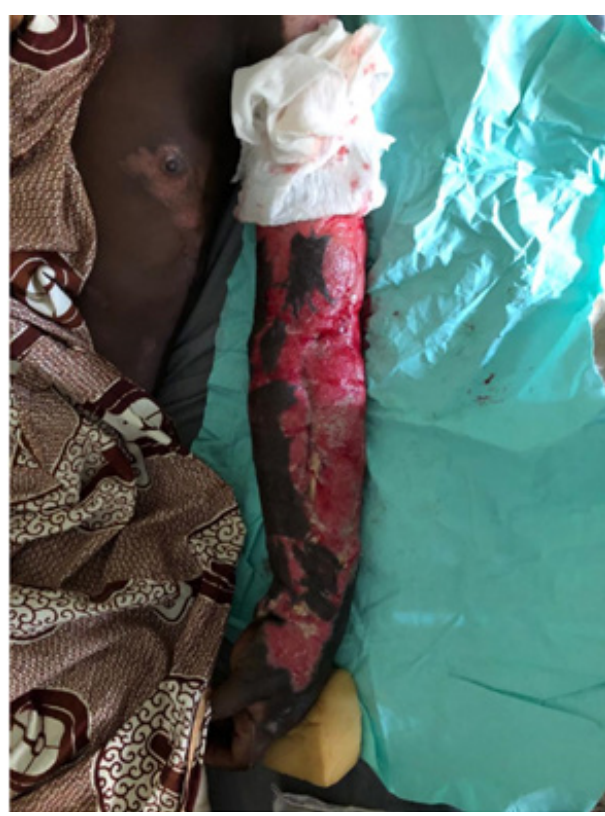

Figure 57 Days post split-thickness skin graft.

7 days post- skin graft surgery, physiotherapy sessions were started (Figure 6).

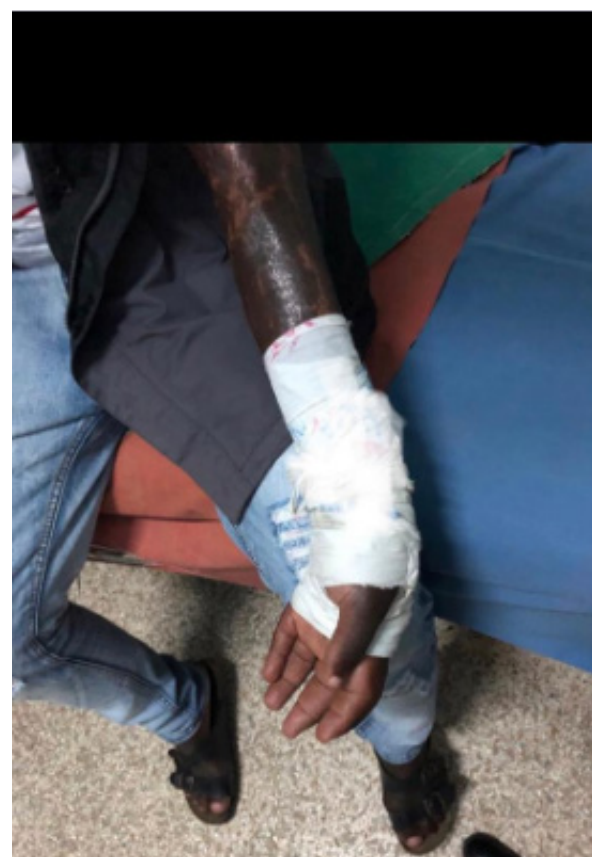

Figure 6 Patient 6 months post injury. With a wrist brace.

\section{Case 2}

A 35 week old preterm child with an extravastion injury to the posterior aspect of the left ankle (Figure 7).

The wound was irrigated with saline and the Homemede VAC dressing was applied (Figure 8). The 2 hours on, and 1 hour off, regimen was employed with the suction pressures kept at between $50 \mathrm{mmHg}$ and $75 \mathrm{mmHg}$.. The change of dressing was done every five days. The wound healed by day 15 without any need for split thickness skin grafts. 


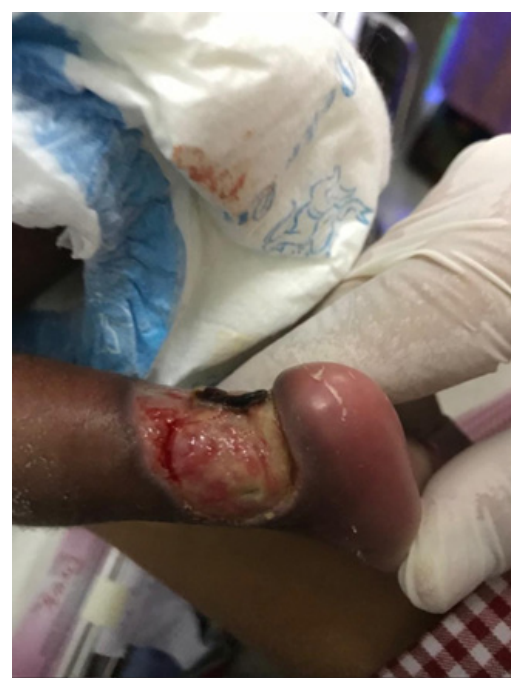

Figure 7 preterm child with posterior ankle ulcer.

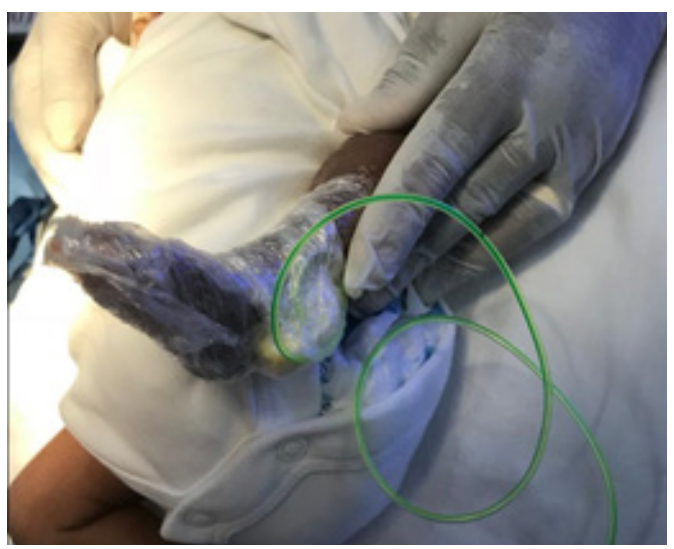

Figure 8 Homemade VAC dressing applied to wound.

\section{Case 3}

This is a 6 year old boy involved in a Road Traffic Accident as a pedestrian. He suffered an avulsion injury to the dorsum of the left foot. The child was brought to the Trauma Emergency 4 days after sustaining the injury. The wound required irrigation and thorough debridement (Figure 9).

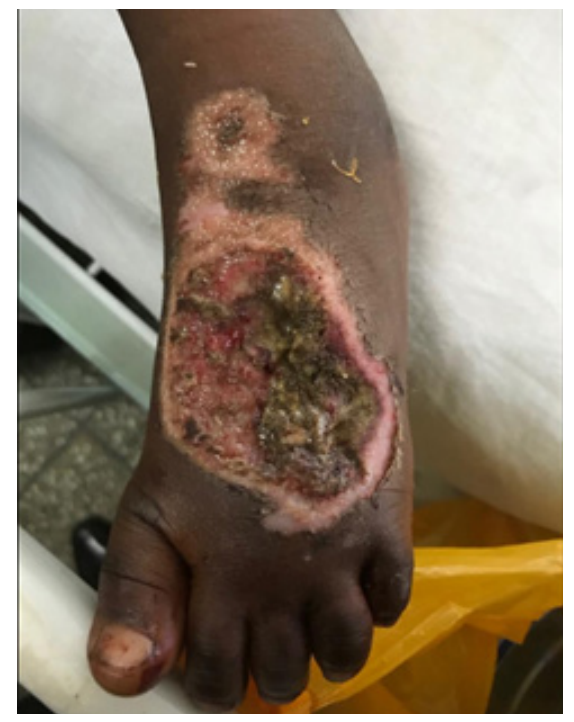

Figure 9 Avulsion injury of the dorsum of the foot.
This was done under general anaesthesia in the operating theatre. The Homemade VAC was applied. The suction pressures were kept at between $75 \mathrm{mmHg}$ and $100 \mathrm{mmHg}$. The change of dressing was done every five days. The wound was inspected on day 10 and was found to have good healthy granulation tissue (Figure 10). A split thickness skin graft was done to cover the wound.

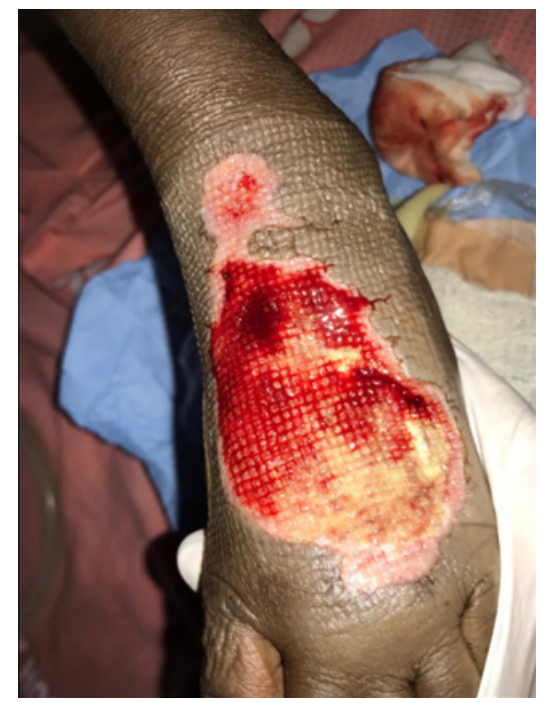

Figure 10 The ulcer with healthy granulation tissue on day 10.

\section{Discussion}

In the year 1995, a commercial system for promoting vacuum assisted closure (VAC) also known as vacuum therapy, vacuum sealing or topical negative pressure therapy, was introduced into the United States market. ${ }^{5}$ This equipment, called the VAC, was designed to overcome some of the problems associated with conventional methods for the creation of negative pressure. The heart of the system is a microprocessor-controlled vacuum unit that is capable of providing controlled levels of continuous or intermittent sub-atmospheric pressure ranging from 25 to $200 \mathrm{mmHg}$. ${ }^{5}$ Unfortunately, this is unavailable or unaffordable to patients in low-income countries. As a result there is the need for improvisation of appropriate technology. In our practice our "home made" vacuum dressing has been found to be, affordable for our patients and most importantly effective in wound management.

\section{Funding}

None.

\section{Acknowledgments}

None.

\section{Conflicts of interest}

The authors declare no conflicts of interest.

\section{References}

1. Robson MC, Steed DL, Franz MG. Wound healing: biologic features and approaches to maximize healing trajectories. Curr Probl Surg. 2001;38(2):72-140.

2. Alonso JE, Lee J, Burgess AR, et al. The management of complex orthopaedic injuries. Surg Clin North Am. 1996;76(4):879-903.

3. Fleischmann W, Strecker W, Bombelli M, et al. Vacuum sealing as treatment of soft tissue damage in open fractures. Unfallchirurg. 1993;96(9):488 492. 
4. Argenta LC, Morykwas MJ. Vacuum-assisted closure: a new method for wound control and treatment: clinical experience. Ann Plast Surg. 1997;38(6):563-577.

5. Steve Thomas. An introduction to the use of vacuum assisted closure 2001 .

6. Banwell P, Withey $\mathrm{S}$, Holten $\mathrm{I}$. The use of negative pressure to promote healing. Br J Plast Surg. 1998;51(1):79.

7. Morykwas MJ, Argenta LC. Nonsurgical modalities to enhance healing and care of soft tissue wounds. J South Orthop Assoc. 1997;6(4):279-288.

8. Fabian TS, Kaufman HJ, Lett ED, et al. The evaluation of subatmospheric pressure and hyperbaric oxygen in ischemic full-thickness wound healing. Am Surg. 2000;66(12):1136-1143.

9. Bauer P, Schmidt G, Partecke BD. Possibilities of preliminary treatment of infected soft tissue defects by vacuum sealing and PVA foam. Handchir Mikrochir Plast Chir. 1998;30(1):20-23.

10. Meara JG, Guo L, Smith JD, et al. Vacuum-assisted closure in the treatment of degloving injuries. Ann Plast Surg. 1999;42(6):589-594.

11. De Franzo AJ, Marks MW, Argenta LC, et al. Vacuum-assisted closure for the treatment of degloving injuries. Plast Reconstr Surg. 1999;104(7):2145-2148.

12. Avery C, Pereira J, Moody A, et al. Clinical experience with the negative pressure wound dressing. Br J Oral Maxillofac Surg. 2000;38(4):343345.

13. Schneider AM, Morykwas MJ, Argenta LC. A new and reliable method of securing skin grafts to the difficult recipient bed. Plast Reconstr Surg. 1998;102(4):1195-1198.
14. Pfau M, Rennekampff HO, Schaller HE. Skin graft fixation by vacuum assisted topical foam dressing. J Burn Care Rehab. 2000;21(1):1.

15. Molnar JA, DeFranzo AJ, Marks MW. Single-stage approach to skin grafting the exposed skull. Plast Reconstr Surg. 2000;105(1):174-177.

16. Collier M. Know-how: a guide to vacuum-assisted closure (VAC). Nurs Times. 1997;4;93(5):32-33.

17. Deva AK, Siu C, Nettle WJ. Vacuum-assisted closure of a sacral pressure sore. J Wound Care. 1997;6(7):311-312.

18. Hartnett JM. Use of vacuum-assisted wound closure in three chronic wounds. J Wound Ostomy Continence Nurs. 1998;25(6):281-290.

19. Baynham SA, Kohlman P, Katner HP. Treating stage IV pressure ulcers with negative pressure therapy: a case report. Ostomy Wound Manage. 1999;45(4):28-32,34-35.

20. Greer SE, Duthie E, Cartolano B, et al. Techniques for applying subatmospheric pressure dressing to wounds in difficult regions of anatomy. J Wound Ostomy Continence Nurs. 1999;26(5):250-253.

21. Mendez-Eastman S. Use of hyperbaric oxygen and negative pressure therapy in the multidisciplinary care of a patient with nonhealing wounds. J Wound Ostomy Continence Nurs. 1999;26(2):67-76.

22. Johansen K, Daines M, Howey $\mathrm{T}$, et al. Jr. Objective criteria accurately predict amputation following lower extremity trauma. $J$ Trauma. 1990;30(5):568-672.

23. Aarabi S, Kavousi Y, Friedrich J, et al. Severe lower extremity injury: MESS (mangled extremity severity score) Twenty-Five Years Later. $J$ Trauma Acute Care Surg. 2016 in press. 